
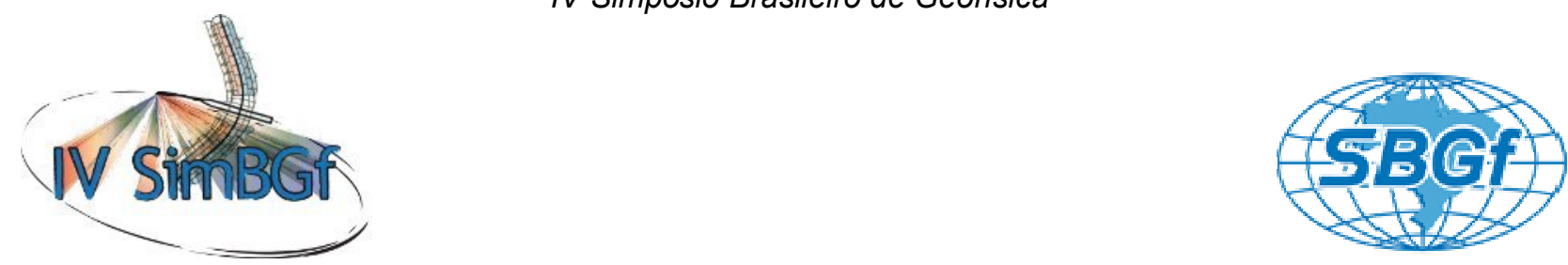

\title{
Uso do GPR no mapeamento geológico do Rio Estrela (RJ) para a travessia do gasoduto GASDUC III
}

\author{
José Tavares Araruna Júnior, Patrício José Moreira Pires, Guilherme Roberto Slongo \& Cláudio Palmeiro do Amaral. \\ Pontifícia Universidade Católica do Rio de Janeiro.
}

Copyright 2010, SBGf - Sociedade Brasileira de Geofísica

Este texto foi preparado para a apresentação no IV Simpósio Brasileiro de Geofísica, Brasília, 14 a 17 de novembro de 2010. Seu conteúdo foi revisado pelo Comitế Tecnico do IV SimBGr, propósitos comerciais sem prévia autorização da SBGf.

\section{Resumo}

O presente trabalho relata um caso recente, a travessia do Rio Estrela km 175 do gasoduto GASDUC III, onde houve um insucesso da instalação do referido duto através da aplicação da técnica de furo direcional horizontal (HDD). O levantamento gpr foi empregado para levantar informações adicionais sobre o meio físico no intuito de diagnosticar o motivo pelo qual o maquinário existente não conseguia alargar o furo além de 30" de diâmetro. O levantamento gpr concluiu que as dificuldades encontradas no alargamento do furo direcional foram, em parte, decorrência do perfil geológico-geotécnico adotado no projeto do furo direcional. O perfil adotado não indicava os diversos matacões que afloram na superfície, nem sugeriam a sua presença em sub-superfície. A presença de matacões de dimensões variadas, e a existência de um perfil de solo heterogêneo, com os mesmos imersos e misturados ao solo residual, por si só, seria suficiente para dificultar as operações.

\section{Introdução}

A técnica de furo direcional horizontal (HDD) é uma solução inovadora para a instalação de dutos de grande extensão sem a necessidade de abertura de valas e a consequente interrupção da faixa na sua parte superficial. A técnica HDD é aplicada em travessias por áreas populosas ou congestionadas, em travessias por áreas de proteção ambiental ou em áreas sensíveis quanto a impactos ambientais, em travessias de regiões sujeitas a ação de movimento de massa e em travessias de obstáculos cuja tecnologia tradicional não se aplique ou traga grandes transtornos ou riscos. No entanto, a sua aplicabilidade está condicionada as condições geológicas, geotécnicas e hidrogeológicas do meio físico.

O estado da prática do levantamento geológico de travessias de rios para instalação de dutos revela que a utilização de ferramentas não invasivas é cada vez mais frequente (Soares, 2009). Entre as ferramentas mais utilizadas encontra-se o radar de penetração (gpr). A literatura técnica revela ser possível, através das informações obtidas por levantamentos gpr, determinar a estatigrafia de perfis terrosos e rochosos (Davis \& Annan, 1989), corroborar nas informações pontuais fornecidas pelas sondagens (Souza et al., 2006) e localizar estruturas/elementos enterradas(os) em áreas de difícil acesso (Araruna Jr. et al., 2002). No entanto, a sua utilização vem sendo alvo de críticas por parte da comunidade técnica, que, por muitas vezes, coloca a sua utilidade em cheque. Segundo lyomasa (2006), a aplicação do gpr de forma indiscriminada e sem critérios técnicos, origina problemas tanto na aquisição quanto na interpretação de seus resultados.

Araruna Jr. et al. (op. cit.) sugerem que o passo mais importante a ser executado no planejamento de um levantamento gpr é a definição do problema. Nesta fase procura-se avaliar previamente a viabilidade de utilização do método. Isto consiste em responder a algumas questões, incluindo: quais são a profundidade e a geometria do alvo, se há contraste suficiente entre as propriedades elétricas, quais as dificuldades da região, se há fontes de ruído eletromagnético (antenas de rádio, torres de alta tensão, ou postes de iluminação) e se existem dados disponíveis de outros levantamentos.

O presente trabalho relata um caso recente, a travessia do Rio Estrela km 175 do gasoduto GASDUC III onde houve um insucesso da instalação do referido duto. O referido duto de 38" de diâmetro deveria ser instalado no local indicado na Figura 1. No entanto, o processo HDD só conseguiu escavar um orifício de 30 " de diâmetro. O levantamento gpr foi empregado para levantar informações adicionais sobre o meio físico no intuito de diagnosticar o motivo pelo qual o maquinário existente não conseguia alargar o furo.

\section{Considerações Acerca da Área de Estudo}

A área de estudo está inserida num domínio de rochas gnáissico-migmatíticas, onde ocorrem importantes corpos graníticos - os Granitos Suruí, Andorinha e Rosa. Nesta área, caracterizada pela presença de morrotes, os granitos afloram sob a forma de campos de matacões arredondados e semi-arredondados conforme pode ser visto na Figura 2.

Em geral, os matacões rochosos têm diâmetro maior que $2,0 \mathrm{~m}$, e aparecem individualizados in situ por dois sets de fraturas tectônicas (NW-SE e NE-SW, sub-verticais) e um set de alívio (mergulho de $32^{\circ}$ para SW). 


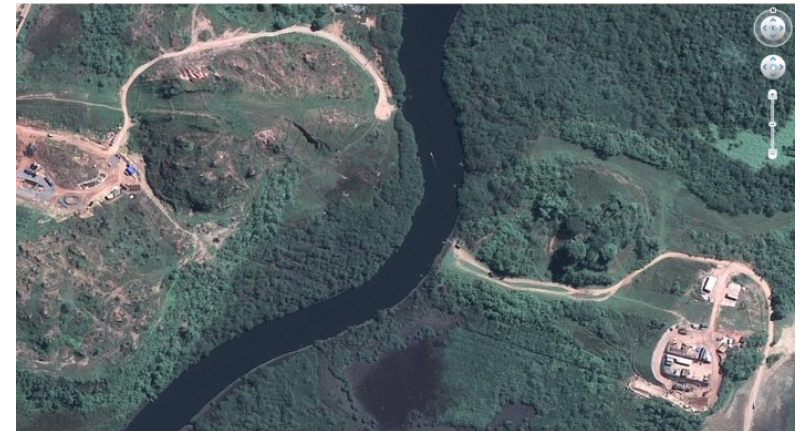

Figura 1 - Vista da área de estudo (imagem Google, setembro de 2009)

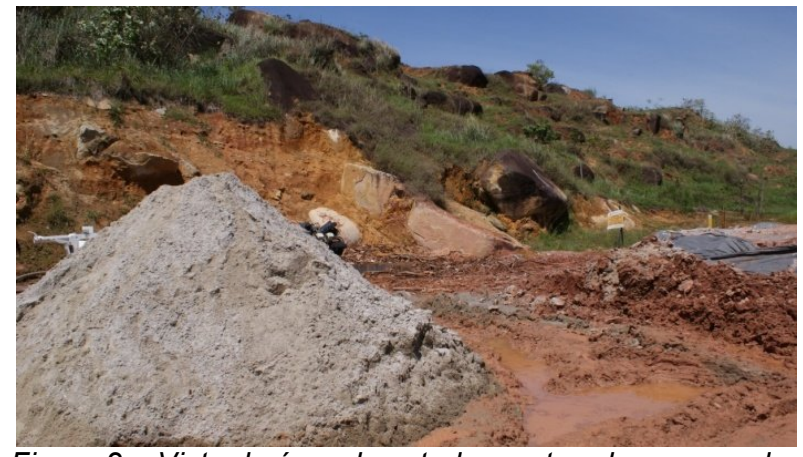

Figura 2 - Vista da área de estudo mostrando campos de matacões graníticos arredondados e semi-arredondados e matacões pegmatíticos

O perfil de solo na área de estudo engloba a presença de solo residual com blocos rochosos imersos e misturados, além de diques pegmatíticos, em transição irregular e tênue para a rocha sã,conforme pode ser visto no diagrama esquemático da Figura 3.

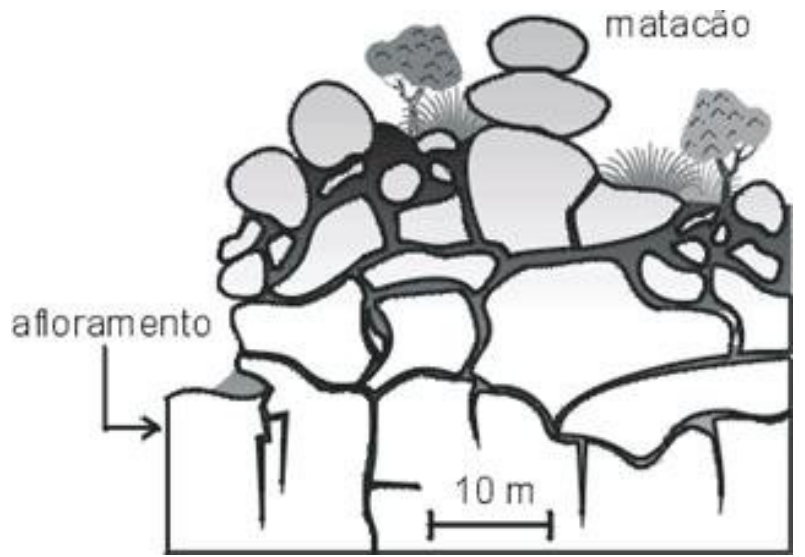

Figura 3 - Diagrama esquemático da geologia da área em questão

Esta configuração é particularmente característica da transição das encostas para a baixada, onde o furo direcional entra e sai, mesmo com o perfil convexo da encosta. Há de se esperar, em função destas propriedades, uma variabilidade significativa da escavabilidade nestes trechos, de 1 a 3.

Este não foi o caso, entretanto, do perfil geológicogeotécnico adotado no projeto do furo direcional. O perfil, apresentado na Figura 4, não indica os diversos matacões que afloram na superfície, e sugere uma pouca quantidade em sub-superfície.

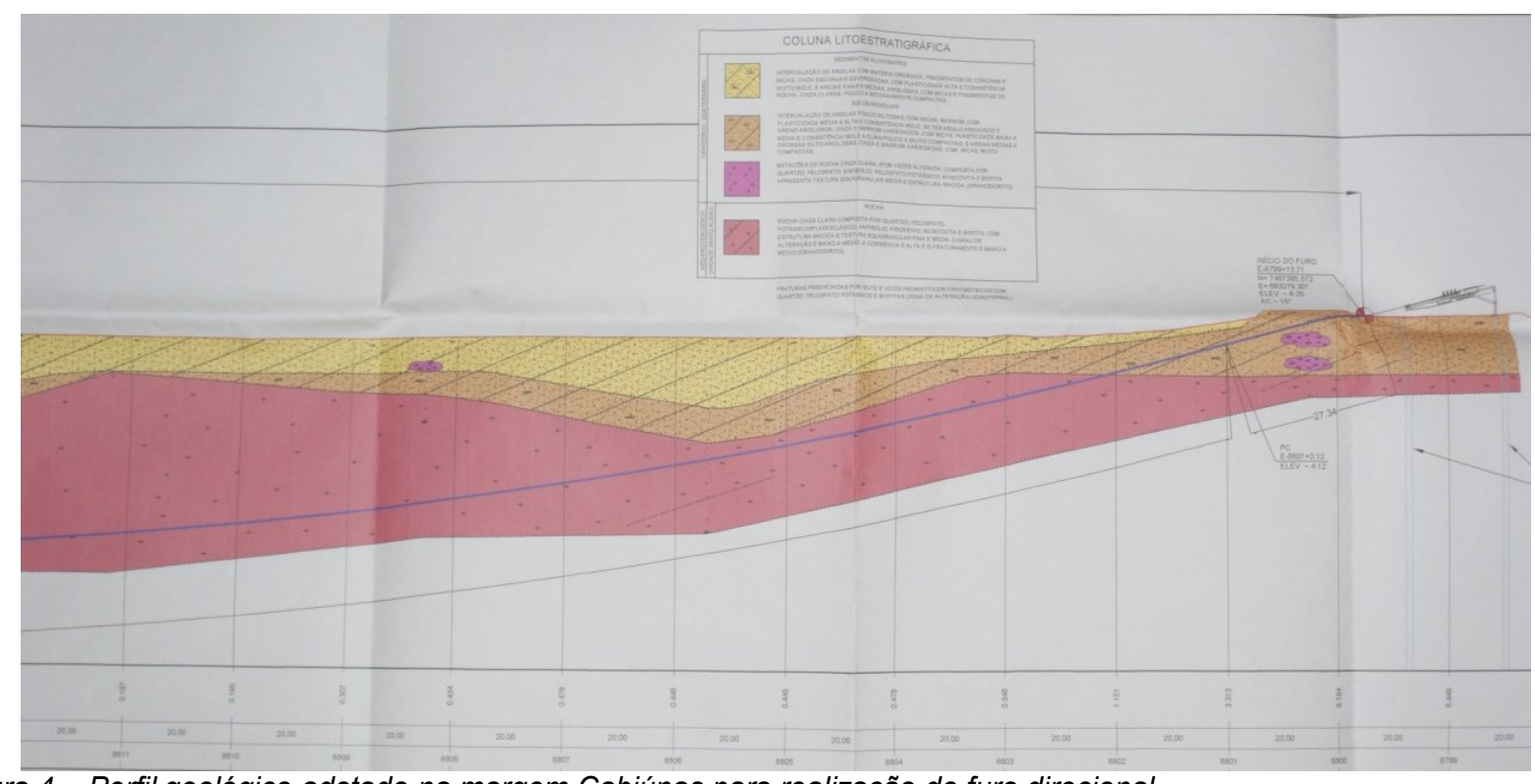

Figura 4 - Perfil geológico adotado na margem Cabiúnas para realização do furo direcional 
A presença de matacões de dimensões variadas, e a existência de um perfil de solo heterogêneo, com os mesmos imersos e misturados ao solo residual, por si só, seria suficiente para tornar a interpretação de sondagens mistas nestas áreas uma tarefa trabalhosa, e a interpretação dos resultados das sondagens geofísicas, muito difícil.

Durante as operações de travessia com furo direcional foi realizado jet grouting, em uma área de $6 \times 6$ metros, para facilitar o avanço das operações de perfuração.

\section{Metodologia Empregada}

O levantamento geofísico foi executado empregando um radar de penetração (gpr) da marca MalaGeoscience, modelo Ramac. O equipamento, visto na Figura 5, consiste de uma unidade de aquisição e controle instalada em uma mochila onde os sinais das ondas eletromagnéticas emitidos e recebidos são transferidos para um monitor, também acoplado a mochila, que permite a visualização dos sinais eletromagnéticos e o seu armazenamento em meio digital.

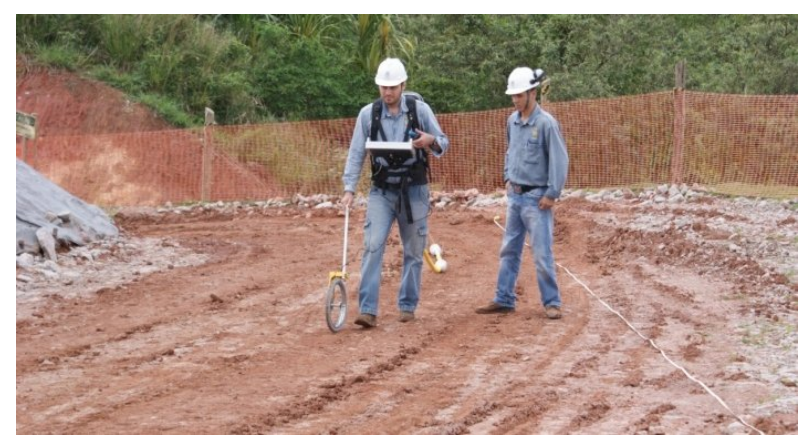

Figura 5 - Equipamento GPR empregado na investigação

O posicionamento das antenas foi realizado através de um odômetro que transmite os sinais eletromagnéticos a unidade de aquisição e controle, e por um sistema de posicionamento global (gps) que permite, através do pacote computacional GPS Mapper ${ }^{\circledR}$, visualizar o posicionamento das sondagens geofísicas no pacote computacional Google Earth ${ }^{\circledR}$.

Os perfis foram adquiridos através da utilização de antenas RTA's (Rough Terrain Antennas). A freqüência central da antena foi escolhida por propiciar uma boa penetração do sinal até a profundidade de interesse e seguiu as orientações disponíveis em Porsani (1999) e Annan \& Cosway (1992). Assim, utilizou-se a antena de $100 \mathrm{MHz}$ na margem Cabiúnas onde a profundidade de interesse era de cerca de $5 \mathrm{~m}$.

A aquisição de dados gpr foi realizada utilizando-se o programa GroundVision $^{\mathbb{Q}}$ e, para a maioria dos perfis, foram adotados os seguintes parâmetros:

- $\quad$ número de amostras por scan (traço) - 1000;

- $\quad$ número de stacks (empilhamento) - 4;
- $\quad$ range (janela temporal) - 200ns;

- $\quad$ intervalo entre scans (traços) - 0,10m;

- sem ganho;

- nenhuma filtragem.

Os dados adquiridos foram processados utilizando-se o programa RadExplorer ${ }^{\mathrm{B}}$. Todos os radargramas obtidos foram processados utilizando-se os mesmos recursos de processamento. Primeiramente, corrigiu-se o atraso da onda direta para a posição zero e, em seguida, os dados foram filtrados com um filtro vertical, IIR filter, para delimitar a faixa de freqüência atingível pela antena utilizada. Uma função de ganho do tipo automática (AGC/SEC) em 10 pontos foi aplicada. Ainda, para uma melhor visualização dos dados, utilizou-se o recurso de ajustar a escala horizontal, skipping, o qual permite especificar o número de scans (traços) a mostrar. Para conversão da escala vertical em tempo (ns) em profundidade $(\mathrm{m})$, foi adotado o valor 9 para a constante dielétrica do material de fundação.

\section{Apresentação e Discussão dos Resultados}

A investigação na área da margem no sentido Cabiúnas foi realizada através da execução de 21 sondagens geofísicas. As sondagens foram realizadas nos sentidos longitudinal e transversal ao alinhamento das tubulações metálicas, vide Figuras 6 e 7 respectivamente.

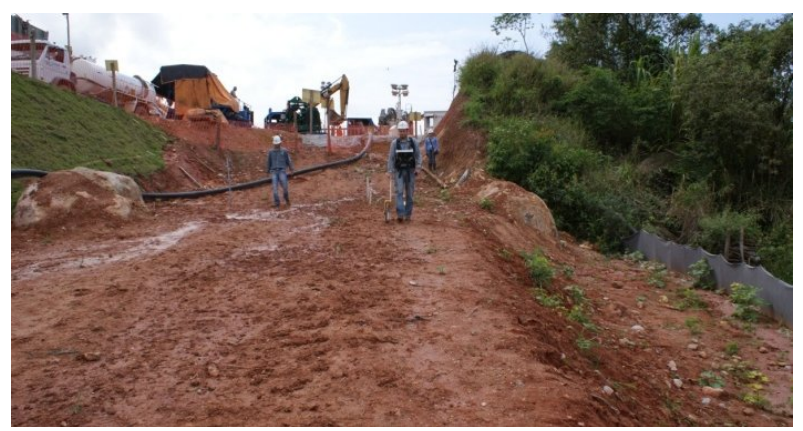

Figura 6 - Levantamento gpr em uma seção longitudinal ao eixo do duto

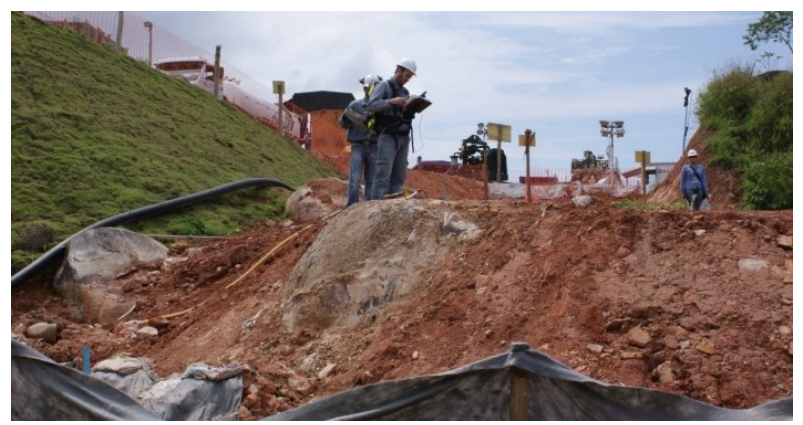

Figura 7 - Levantamento gpr em uma seção transversal ao eixo do duto 
A sondagem 129, cuja localização é vista na linha vermelha da Figura 8 , foi realizada tranversalmente ao eixo do duto a 41,89 metros do início da perfuração. $O$ radargrama associado ao levantamento, visto na Figura 9, permitiu identificar: a) uma interferência que pode ser atribuída a uma tubulação, b) uma interferência que pode ser atribuída a um bloco rochoso e c) uma interferência que pode ser atribuída a área onde foi realizada o jet grouting. Estas mesmas feições também foram encontradas na sondagem 127 localizada a uma distância horizontal de 42,22 metros do inicio do furo direcional.

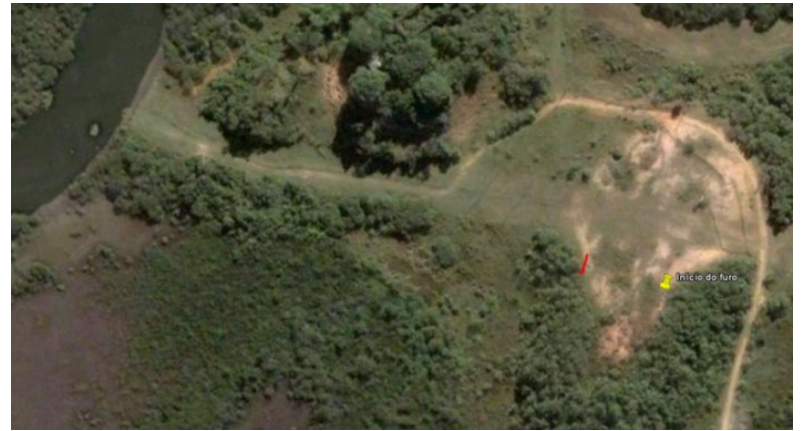

Figura 8 - Localização da seção 129

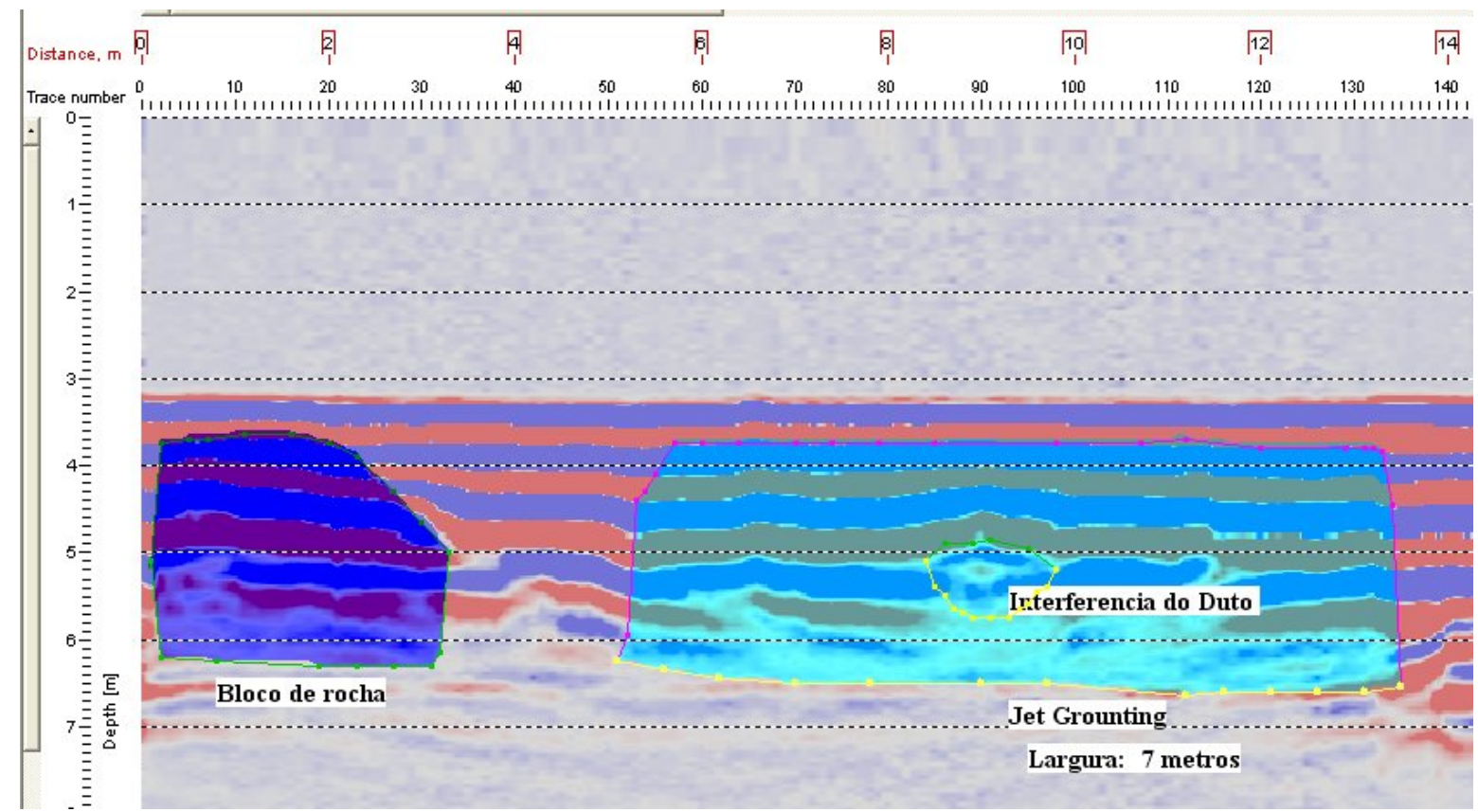

Figura 9 - Radargrama da seção 129

A sondagem 150, cuja localização é vista na linha vermelha da Figura 10, foi realizada transversalmente ao eixo do duto a uma distância horizontal de 30 metros do início da perfuração. O radargrama associado ao levantamento, visto na Figura 12, permitiu identificar uma interferência que pode ser atribuída a uma tubulação, como também uma interferência localizada ao lado do duto. Esta interferência, formada por hipérboles justapostas, está localizada na mesma profundidade do duto. Também foi possível identificar uma interferência que pode ser atribuída a provável superfície do jet grouting.

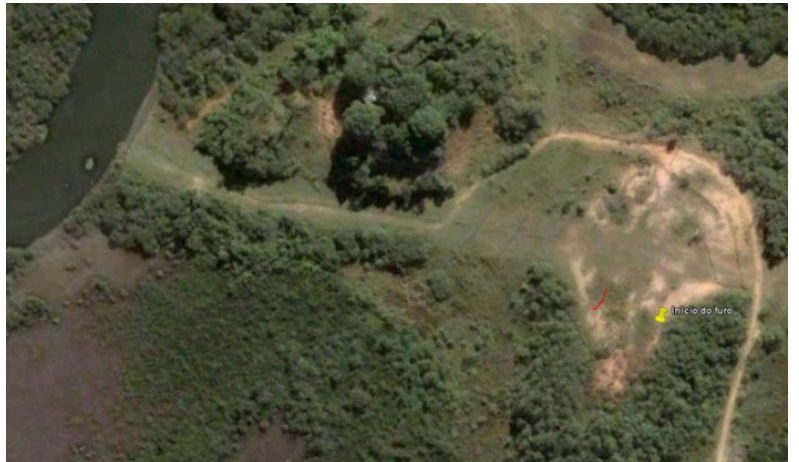

Figura 10 - Localização da sondagem 150 
Esta interferência também foi detectada na seção longitudinal 138, vista na Figura 13, cujo início se deu a uma distância horizontal de 23 metros do início da perfuração (vide Figura 11). Esta interferência poderia estar relacionada com um dos bicos injetores do equipamento de jet grouting, cujo processo encontra-se detalhado no diagrama esquemático na Figura 14, que foi perdido durante o processo de melhoria do terreno. A escavação realizada após a conclusão do levantamento gpr revelou que este era o caso.

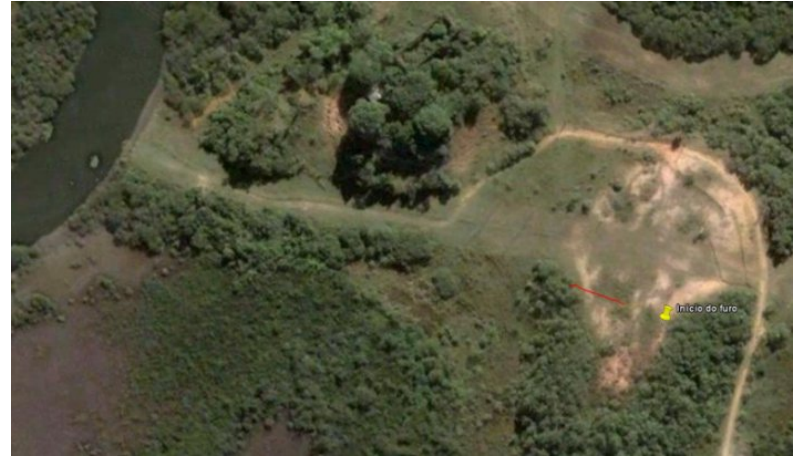

Figura 11 - Localização da sondagem 138

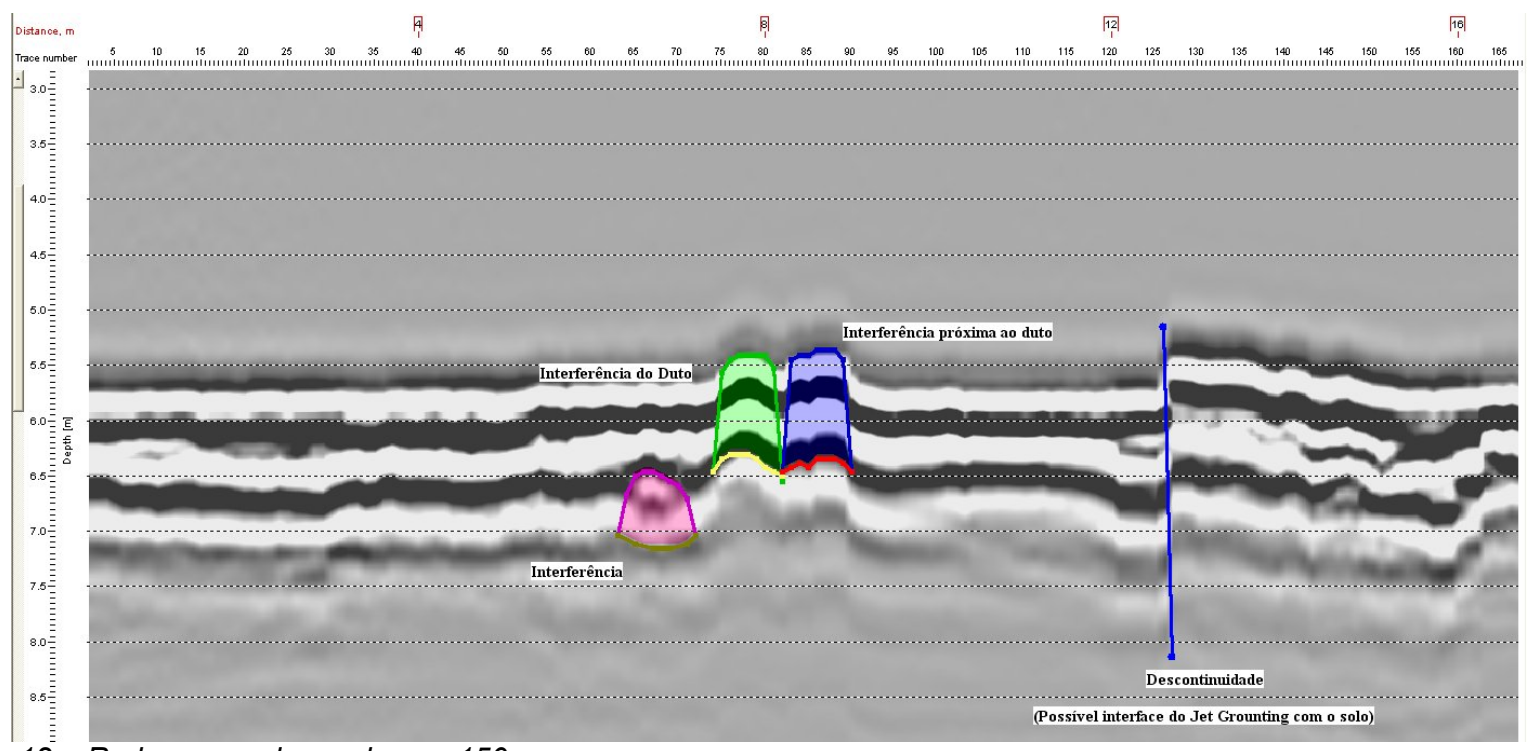

Figura $12^{\prime}-$ Radargrama da sondagem 150

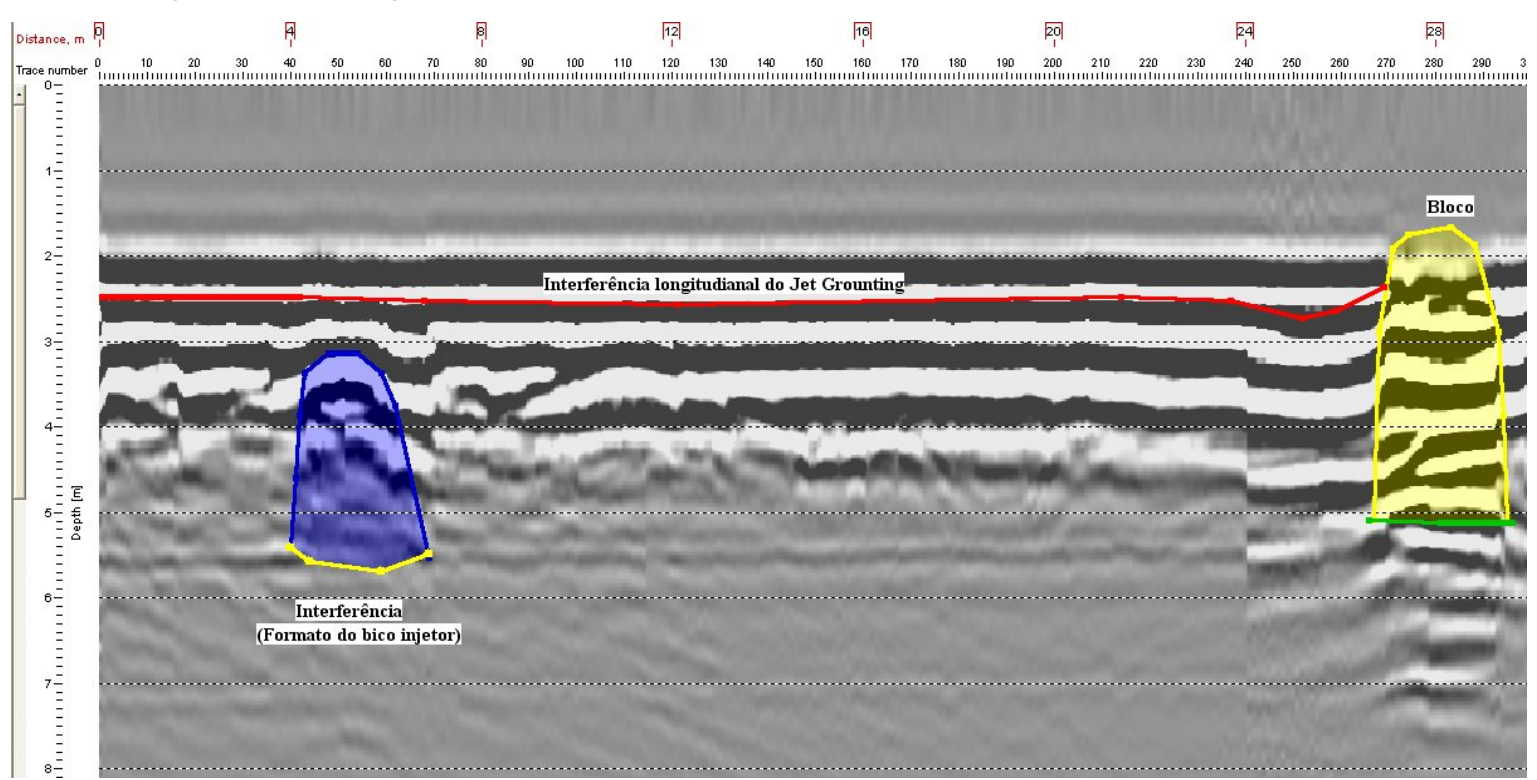

Figura $13^{-}$- Radargrama da sondagem 138 


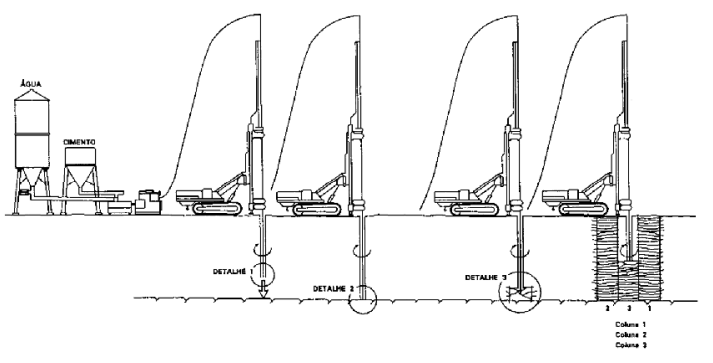

Figura 14 - Diagrama esquemático do processo de jet grouting (Carreto, 2000)

\section{Considerações Finais}

O levantamento gpr concluiu que as dificuldades encontradas no alargamento do furo direcional foram, em parte, decorrência do perfil geológico-geotécnico adotado no projeto do furo direcional. O perfil adotado não indicava os diversos matacões que afloram na superfície, nem sugeriam a sua presença em sub-superfície. A presença de matacões de dimensões variadas, e a existência de um perfil de solo heterogêneo, com os mesmos imersos e misturados ao solo residual, por si só, seria suficiente para dificultar as operações. Esta característica do meio físico também dificultou a interpretação dos resultados das sondagens geofísicas posto que as feições típicas de uma interferência provocada por um tubo metálico em um radargrama, i.e. feições hiperbólicas, são semelhantes à de blocos rochosos.

Os radargramas associados às sondagens realizadas na margem Cabiúnas do Rio Estrela permitiram a identificação de um vazio próximo a interferência típica de uma tubulação a uma distância horizontal de 23 metros do início da perfuração. Esta interferência poderia estar relacionada com um dos bicos injetores do equipamento de jet grouting que foi perdido durante $o$ processo de melhoria do terreno. A escavação realizada após a conclusão do levantamento gpr revelou que este era o caso. No entanto, esta peça estava a uma distância razoável do furo do duto e não atrapalhou o processo de seu alargamento.

\section{Referências}

Annan, A.P. \& Cosway, S.W. (1992). Ground penetrating radar survey design. Proceedings of the Symposium on the Application of Geophysics to Engineering and Environmental Problems, vol. 2, pp. 329-352.

Araruna Jr., J.T.; Nunes, C.M.; Costa,A. \& Vargas Jr., E.A. (2002). O emprego do radar de penetração (gpr) na detecção de elementos de fundação. Anais do XII Congresso Brasileiro de Mecânica dos Solos e Engenharia Geotécnica, São Paulo, vol. 1, pp.135-146.
Carreto, J.R. (2000). Jet Grouting: uma técnica em desenvolvimento. Anais do VII Congresso Português de Geotecnia, pp. 1043-1054.

Davis, J.L. \& Annan, A.P. (1989). Gound penetrating radar for high resolution mapping of soil and rock statigraphy. Geophysical Prospecting, vol. 37, pp. 531551.

lyomasa, W.S.; Galli, V.L.; Blanco, R.G \& Campos, G.C. (2006). O uso do radar de penetração no solo para localização de dutos em áreas urbanas: potencialidades e limitações. Revista Solos e Rochas, vol. 29, número 2, pp. 177-188.

Porsani, J.L. (1999). Ground penetrating radar (gpr): proposta metodológica de emprego em estudos geológicos-geotécnicos nas regiões de Rio Claro e Descalvado - SP, Tese de Doutorado, Instituto de Geociências e Ciências Exatas, UNESP, Rio Claro, 145p.

Soares, A.C.C.P.P. (2009). Métodos geofísicos em obras lineares. Dissertação de Mestrado. Programa de PósGraduação em Engenharia Civil da Pontifícia Universidade Católica do Rio de Janeiro, 127p.

Souza, M.M; Araruna Jr., J.T., Antunes, F.S. \& Ferreira, C.M. (2006). O uso do gpr para detecção de vazamentos de água. Estudo de caso: Parque Gráfico do Jornal $O$ Globo. Anais do XIV Congresso Brasileiro de Águas Subterrâneas, Curitiba. 